\title{
When Rubrics Collide: One Undergraduate Writing Tutor's Experience Negotiating Faculty and Institutional Assessments
}

\author{
Kelli Martin, BA \\ BSEd Candidate \\ Park University
}

This article recounts one undergraduate writing tutor's experience helping a fellow peer navigate an institutional assessment rubric that seemed to contrast the assessment criteria provided by the student's instructor. This article presents a reflection on that experience, framed by Hutchings, Huber, and Ciccone's (2011) work on institutional assessment and the scholarship of teaching and learning.

I had just started my shift in the academic support center, and I was waiting for one of my regular students to show up for writing tutoring. Jana had met with me nearly every week since I started working at the University as a peer writing tutor. Normally, Jana brought with her a rough draft for me to read, or a highlighted assignment sheet with notes detailing her ideas for a topic. However, this day was different. As she came plodding in, I questioned where her bubbly personality was hiding and why she looked so grim. She flopped the 11-page assignment sheet on to the table. It had no highlighting, and her only notes were a series of question marks in the left margin. She stared past me through the whites of her eyes. Her forehead rested in the palms of her hands. She nearly cried: "I have no idea what I'm supposed to do." While it was disconcerting to see Jana crumble in the face of an assignment, I remained optimistic and confident. As a tutor for nearly six years, first at the community college and now at the university level, there were few approaches I had not seen. Except this time.

When I glanced down at the assignment sheet, I saw two rubrics, each containing different criteria and language and, at points, seemingly conflicting descriptions. One rubric was a template provided by the institution, and the other was written by Jana's instructor. Although I had often helped mediate student frustration with assignments, I had never before encountered a set of conflicting rubrics for a single assignment. Years of training, both as a writing tutor and preservice secondary education teacher, did not prepare me to understand what I was seeing - a conflict that echoed far outside the confines of the tutoring session.

That day with Jana immediately came to mind when I read Hutchings, Huber, and Ciccone's (2011) chapter, "The Scholarship of Teaching and Learning Meets Assessment," in the collection Learning Reconsidered: Institutional Integration and Impact. Jana's experience stands as a perfect example of how institutional assessment and the efforts of individual instructors to document student performance at the course level often collide on the pages of a syllabus, with consequences for students. As the authors observed, "the connection [between the scholarship of teaching and institutional assessment] sometimes feels fragile, and purposes are often different, even at odds" (Schodt, qtd in Hutchings, Huber, and Ciccione, 2011, p. 72).

In Jana's case, neither the instructor nor the institution harbored ill intentions. On the contrary, her instructor's rubric was written for students - to describe and foster self-assessment of their working knowledge of the content. In contrast, the institution's rubric, while it seemed written primarily for faculty and administrative audiences, had an equally laudable goal: to enable the comparison of student outcomes across course sections and modalities, online and face-to-face. The different audiences and uses for the rubrics illustrated the reality that although 
[b]oth the scholarship of teaching and learning and assessment are dedicated [to] being more public about the learning that happens (or does not) in college and university classrooms, and to making that learning visible....the publics they have in view can be quite different (Hutchings, et al., 2011, p. 69).

My background as a preservice English teacher has also made me aware of the tensions that exist between classroom and institutional approaches to student learning assessment. My student teaching practicums have exposed me to a diverse array of learners in the high school setting and, ironically, a distinct lack of variety in the summative assessment instruments used to measure their learning. Nowhere is this disconnect more apparent than with the students I primarily work with: English language learners. Often these students have a very good working knowledge of disciplinary content but lack the linguistic skills to read a multiplechoice test or write an essay question. Does a student challenged to express his or her above-average content knowledge, due to poor reading and writing skills, deserve a lower score than the student with exemplary writing skills but only marginal understanding of the content? Assessments which can parse the differences between linguistic skills and academic content knowledge are rare, and certainly not easily adapted to district- or state-wide implementation. While the results of these authentic assessments serve the purposes of classroom teachers, they are difficult to represent on a spreadsheet. As Hutchings, Huber, and Ciccone (2011) pointed out, "[course assessments] may yield densely qualitative data that do not resolve into neat findings" (p. 74). However, the possibility exists for institutional assessment to strengthen, and be strengthened by, course assessments which seek the kind of nuanced understanding of learners described above. Through collaboration among administrators, faculty, and students, assessments can be devised that generate the numbers needed for large-scale implementation and reporting and still have meaning for instructors and for students like Jana.

Of all I have learned about being a future educator, perhaps the most useful has been the ability to translate standards into measurable objectives, and to then use those objectives to produce an assessment scale. Such assessment training, while not always a part of the education of post-secondary faculty, is valuable: It not only provides a means of untangling "messy" qualitative data, but it also helps teachers find a use for quantitative data in their own instructional and scholarly explorations of student learning. Perhaps this is the crux of the conflict Jana and I witnessed: Where the institution wanted to see definitions and examples of terminology, quantifiable and generalizable, the instructor wanted to measure phenomena far more qualitative. Where the institution wanted to focus on what was perceived as measurable (for instance, the number of sources incorporated into the essay assignment, or the number of grammatical errors crossing the line between "meets" and "does not meet" expectations), the instructor wanted more room for those elements of writing less amenable to quantification. Although faculty "may have a hard time seeing how institutional scores and results relate to their plans for Monday morning's class or for their department's curricular redesign" (p. 73), Hutchings, Huber, and Ciccone argue that the challenge of accepting and adapting institutional assessment is worth the work. In the field of education, preservice teachers are taught that these objectives come from standards. Higher education faculty can use this same process to analyze disciplinary standards, develop content objectives, and then work in collaboration with administrators to represent those assessment criteria in ways that serve both internal and external audiences.

In Park University's School for Education, there is a mantra which every student knows well: assessment for learning, not of learning. This mantra is modeled on the ideas of Stiggins, Arter, Chappuis, and Chappuis (2007), who focused on the importance of formative assessment and the practical use of data 
from large-scale assessments. This is where instructors and teachers could gain insight from institutional assessment and its emphasis on reflection and action to "close the loop." For example, nearly every semester I watch collaborating teachers at my internships stress over standardized tests. Then, as soon as the testing is over, they seem to forget about the exam altogether. Months and sometimes years pass before results from such tests come back, and by then the data is history. Arguably, such teachers lack a perspective on the value of summative assessment data in promoting curricular and instructional change. As Hutchings, Huber, and Ciccone pointed out, institutional assessment offices can engage with individual faculty to assist in interpreting and acting on data; such partnerships can transform assessment from a top-down mandate to a collaborate effort central to academic quality.

As teachers and tutors, we preach self-reflection, but how often do we follow that model, and how can institutional assessments help keep us honest? Collaboration between faculty and administrators opens up the potential for assessment to be used for wide-scale professional development. Through assessment data, teachers can reflect on what they teach well, and where they need to focus their professional development efforts: "Teachers need a chance to step back from their own practice and see students' work and their own anew, from a different angle and altitude" (Hutchings, et al., 2011, p. 78). I understand that raw data can be the least biased source of feedback I may ever receive as a teacher. Institutional assessments, due to their scale, can demonstrate patterns of student learning that force teachers to review, reflect, and revise their approaches.

Most importantly, Hutchings, Huber, and Ciccone reassure that university and faculty, in their course-level assessment, do not have to fight against one another (p. 72). In reality, institutional assessment and the scholarship of teaching and learning can work together when they have common objectives. As a future English teacher, I see the Common Core State Standards Initiative (www.corestandards.org/) as a prime example of the two types of assessment working together. These standards provide the consistent goals that districts crave. For teachers, common core standards are the real-world application, with the greatest potential for measurement, allowing learning to be put into use-oriented terms.

Hutchings, Huber, and Ciccone offer collaboration as the essential solution to creating an environment in which the scholarship of teaching and learning works with institutional assessment to achieve harmony and create bridges between internal and external audiences. One exemplar of this collaborative approach which they discuss in detail is the Carnegie Foundation's project Strengthening PreCollegiate Education in Community Colleges. This group brings a variety of people together to collaborate on goals for student learning and strategies for meeting these goals. Members of this group include administrators, full-time faculty, adjuncts, counselors, and even students. What I appreciate most about this process is the fact that students are not excluded from offering suggestions for goals and strategies. When students are involved in making decisions, assessment is more likely to meet and reflect their needs.

I propose opening participation in such collaborations to peer tutors. Tutors from all disciplines have much to contribute to the conversation on objectives, especially because we often supplement the instruction of teachers or scaffold the information for struggling students. Additionally, these opportunities are important for tutors aspiring to be future classroom educators, as such collaboration builds understanding of learning objectives and the importance of creating connections between classroom and institution. Colleges and universities could create much more effective institutional assessments, without sacrificing accreditation or various other outside pressures, if they could collaborate with a variety of groups to construct learning objectives that satisfy the needs of administrators without imposing on the scholarship of learning. This is necessarily collaborative work. 
I often tell the students I work with at the high school and college level, "writing is a process." This principle applies to writing an assessment, too. Just as an essay needs a thesis as a strong foundation, assessments need objectives to maintain focus. Agreement on these objectives makes the evidence and support for an assessment stronger. After the assessment is drafted and tested, it will inevitably need revision based on feedback from diverse stakeholders. Neither instructors nor institutions are capable of constructing a perfect assessment. Everyone, including Jana and me, can contribute to bridging that gap between the scholarship of teaching and learning and institutional assessment.

\section{References}

Hutchings, P., Huber M.T., \& Ciccone, A. (2011). The scholarship of teaching and learning reconsidered: Institutional integration and impact. San Francisco: J ossey Bass.
Stiggins, R., Arter, J., Chappuis, J., and Chappuis S. (2007). Classroom assessment for student learning: Doing it right-using it well. New York: McGraw-Hill.

Kelli Martin is currently a senior at Park University, double majoring in English Literature and Secondary Education. Martin also works as a peer writing tutor at Park University and Metropolitan Community College - Maple Woods in Kansas City, Missouri. She currently serves as secretary for the Park University chapter of Sigma Tao Delta, the international English honors society as well as secretary of Park University's chapter of ASCD, an organization which develops programs, products, and services for educators and preservice educators. 